\title{
USOS DA MEMÓRIA: AS EXPERIÊNCIAS DO HOLOCAUSTO E DA DITADURA NO BRASIL
}

\author{
Cristiano Paixão \\ Faculdade de Direito da Universidade de Brasília. Brasília, DF. Brasil, \\ E-mail<cristiano.paixaobsb@gmail.com> \\ Giovanna Maria Frisso \\ Departamento de Direito da Universidade Federal Fluminense (UFF/RJ), \\ Rio de Janeiro,RJ.Brasil.E-mail < giovanna_frisso@hotmail.com >
}

http://dx.doi.org/10.1590/ 0102-6445191-212/97

Observa-se hoje uma série de esforços voltados para a recuperação da memória do período ditatorial no Brasil. Criada no dia 16 de maio de 2012, a Comissão Nacional da Verdade (CNV) teve como objetivo examinar e esclarecer as graves violações de direitos humanos praticadas entre 18 de setembro de 1946 e 5 de outubro de 1988, a fim de efetivar o direito à memória e à verdade histórica e promover a reconciliação nacional (Lei $n^{0}$ 12.528/2011). A CNV, que apresentou seu relatório final em 10 de dezembro de 2014, deu continuidade ao trabalho realizado, em âmbito federal, pela Comissão Especial sobre Mortos e Desaparecidos e pela Comissão de Anistia e, em âmbito estadual, pelas inúmeras comissões estabelecidas com o propósito de reconhecer as violações de direito. É diante desses esforços que Paulo Abrão (2012, p. xx), presidente da Comissão de Anistia, afirma a possibilidade de uma evolução na compreensão do significado da anistia, "que passa a ser lida enquanto memória”.

A crescente revalorização da memória no século XX exige refletir não apenas sobre as possibilidades da memória, 
mas também acerca dos riscos relacionados ao seu uso. O que pode ser entendido por memória na Resolução da Assembleia Geral das Nações Unidas, que estabeleceu o dia 27 de janeiro como o Dia Internacional em Memória das Vítimas do Holocausto: trata-se de uma memória oficial, apropriada/produzida pelo discurso histórico, dos testemunhos de sobreviventes? Uma memória revisitada? A memória é evocada para quem? Trata-se de uma memória que auxilia as vítimas e sobreviventes na superação das violações sofridas ou uma memória que visa instruir as pessoas sobre o passado? Qual o potencial da memória ante a (in)ação da comunidade internacional?

Este artigo apresenta algumas reflexões acerca dessas questões no que diz respeito à memória de um evento traumático: o holocausto. Após a Segunda Guerra Mundial, o nazismo alemão ocupou um lugar de proeminência na explosão contemporânea de memória. A maior parte dos 192 atos de reminiscência do holocausto foi associada à resistência ao totalitarismo: o potencial democrático da memória de informar a comunidade internacional acerca da violação sistemática e/ou generalizada de direitos foi evidenciado. Busca-se, assim, recuperar as reflexões geradas pelas discussões em torno do holocausto para lançar luz acerca do potencial (anti)democrático da(s) memória(s) do período ditatorial brasileiro.

O texto está organizado em quatro seções. A primeira considera a relação entre linguagem e memória a partir dos limites que o holocausto apresentou para a comunicação. A segunda seção explora como o Terceiro Reich buscou impedir a construção de uma memória, inclusive pelo abuso da linguagem. A terceira explora os usos potenciais de uma memória que, apesar de todos os empecilhos, se constituiu e é hoje compartilhada por meio da linguagem. E a última seção alerta para os riscos de uma interpretação literal da memória, a qual, ao reduzir a realidade à díade vítima $\mathrm{x}$ per- 
petrador, pode impedir o reconhecimento de que pertencemos todos à mesma humanidade. Com essa estrutura, este artigo busca ressaltar alguns dos desafios encontrados para a realização do potencial democrático da memória, sobretudo da memória de eventos traumáticos.

A partir da discussão da memória do holocausto, que teve o ano de 2015 como marco dos setenta anos da libertação de Auschwitz, o artigo busca chamar a atenção para a necessária reflexão acerca do potencial que a memória do período ditatorial brasileiro apresenta para a promoção da reconciliação nacional. A relação entre memória e reconciliação, entre memória e democracia não é uma relação automática. Ela é construída, fragilmente, lentamente, a partir do fortalecimento de uma esfera pública inclusiva, capaz de tematizar e discutir o período ditatorial. O diálogo é importante para a construção de uma memória que possa reconhecer processos de vitimização e, ao mesmo tempo, afirmar a humanidade de todos.

\section{O contexto comunicativo das memórias traumáticas}

Halbwachs, já no início do século XX, destacou a necessidade de se analisar a memória como um fenômeno social, construída coletivamente e passível de constantes transformações. Buscando esclarecer a posição de Halbwachs, afirma Duvignaud (2006, p. 12):

É claro, a memória individual existe, mas está enraizada em diferentes contextos que a simultaneidade ou a contingência aproxima por um instante. A rememoração pessoal está situada na encruzilhada das redes de solidariedades múltiplas em que estamos envolvidos. Nada escapa à trama sincrônica da existência social atual, e é da combinação desses diversos elementos que pode emergir aquela forma que chamamos lembrança, porque a traduzimos em uma linguagem. 
Halbwachs (2006, p. 39) enfatiza que a memória "é resultado do movimento do sujeito no ato da memorização, como também é ação dos diversos grupos sociais em suas histórias, o passado e presente" ${ }^{\text {. }} \mathrm{O}$ autor compreende a memória coletiva como um elemento essencial para a vivência social, por realizar reinvenções do passado que fornecem fundamentos para que seres humanos interpretem e vivenciem o presente e, a partir de então, visualizem a construção de projetos capazes de modificar o futuro. Na linha durkheimiana, Halbwachs, longe de ver na memória coletiva uma imposição, uma forma específica de dominação, acentua as funções positivas desempenhadas pela memória comum - e, entre elas, a de reforçar a coesão social. É conferido à memória coletiva o atributo de atividade natural, espontânea, seletiva, porém desinteressada. Ao contrário, a história (memória histórica) constitui um processo interessado, político e manipulador.

194 Contudo, o reconhecimento exclusivo da função política de controle desinteressado do passado (e do presente) pela memória coletiva pode inibir ou coibir o reconhecimento dela, a memória coletiva, em suas outras funções políticas (Seixas, 2001, p. 44). Nesse particular, pode-se observar que o período de descolonização retrata a emergência de um novo discurso sobre a memória. A memória coletiva, voluntária, formada no período colonial é incapaz de responder às perguntas dos movimentos sociais locais: as imagens por eles vivenciadas e suas relações sociais não compunham a memória coletiva desse período. O período

1 De acordo com esta perspectiva, Eclea Bosi (1987, p. 17) afirma: "a memória do indivíduo depende do seu relacionamento com a família, com a classe social, com a escola, com a Igreja, com a profissão, enfim, com os grupos de convívio e os grupos de referência peculiares a esse indivíduo". A autora observa, pela perspectiva da psicologia social, que qualquer alteração do ambiente atinge a qualidade íntima da memória, atrelando a memória de uma pessoa à memória do grupo, pois ambas não se dissociam por estarem imbricadas pela situação social à qual as pessoas estão expostas. 
posterior, de descolonização, exigiu, assim, a diluição da distinção entre memória coletiva e memória histórica. Tem início um processo de questionamento da oposição memória individual/memória coletiva pautada exclusivamente no componente da subjetividade ou do desinteresse. Esse processo permite (re)construir identidades.

A partir de então, reconhece-se que memórias se constroem e se multiplicam comunicativamente, a partir de um processo que exclui um início primordial, mas permite a invenção de pontos, marcas, símbolos de fundação (De Giorgi, 2006, pp. 49-73). É justamente nesse contexto que as comissões da verdade atuam. Ao (re)contextualizar a memória na história, elas permitem que terroristas sejam vistos como combatentes pela liberdade (Sontag, 2011, p. 137). O status de vítima daqueles que, por lutarem por uma transformação política, tiveram seus direitos violados pelo Estado é reafirmado. O sucesso desse processo exige um contexto comunicativo, seja entre indivíduos, grupos ou Estados.

O instrumento decisivamente socializador da memória é a linguagem. Ela reduz, unifica e aproxima no mesmo espaço histórico e cultural a imagem do sonho ${ }^{2}$, a imagem

\footnotetext{
2 Em relação ao sonho como fonte da história, Koselleck (2006b, p. 252) traz interessante análise acerca de dois sonhos durante o Terceiro Reich. Diz-nos o autor: "São sonhos sobre o terror, ou, dito de forma mais agressiva, sonhos do terror. O terror não só provoca sonhos; os próprios sonhos fazem parte dele. As duas histórias reproduzem uma experiência que penetrou profundamente nas pessoas; contêm uma verdade interior que se realizou no Terceiro Reich e, mais do que isso, foi desmedidamente superada. Essas histórias sonhadas não só testemunham o terror e suas vítimas; hoje podemos dizer que elas constituíam um presságio.” Reproduz-se a seguir um dos sonhos comentados e analisados por Koselleck, o de um advogado judeu: "dois bancos existem no Tiergarten, um verde, como de costume, e o outro amarelo (os judeus, então, só podiam sentar-se em bancos pintados de amarelo), e entre os dois há um cesto para papel. Sento-me no cesto e eu mesmo penduro no pescoço um letreiro, como fazem por vezes os mendigos cegos e como também as autoridades obrigam os 'violadores da raça' a fazer: 'Se for necessário, deixarei lugar para o papel'”.
} 
lembrada e as imagens da vigília atual. Os dados coletivos que a língua sempre traz em si entram até mesmo nos sonhos (situação limite da pureza individual). De resto, as imagens do sonho não são, embora pareçam, criações puramente individuais. São representações, ou símbolos, sugeridos pelas situações vividas em grupo pelo sonhador: cuidados, desejos, tensões (Bosi, 1987, pp. 18, 19).

A linguagem é elemento fundamental na socialização da memória. E quando a linguagem mostra-se insuficiente? Como refletir acerca da memória traumática, sobre a experiência do choque, sobre a impossibilidade para a linguagem cotidiana e para a narração tradicional de assimilar o trauma da experiência nos campos de concentração? Essa dificuldade é retratada no testemunho de Améry:

Seria como um ferro em brasa em meus ombros e como uma estaca de madeira rombuda enfiada na base de meu crânio? - uma alegoria apenas representaria alguma outra coisa, e no final seríamos levados pelo cabresto em um inútil carrossel de comparações. Dor - era isso. Não há mais nada que se possa dizer. As qualidades do sentimento são tão incomparáveis quanto indescritíveis. Elas assinalam o limite de comunicar da linguagem (apud Power, 2004, p. 68)

Ou, ainda, no sonho de Primo Levi (2004), sonho sonhado, descobre ele, por quase todos os seus companheiros a cada noite. Levi sonha com a volta para casa, com a felicidade intensa de contar aos próximos o horror vivido e passado e, de repente, com a consciência desesperada de que ninguém o escuta, de que os ouvintes levantam e vão embora indiferentes. O sofrimento de cada dia se traduz, constantemente, em seus sonhos, na cena sempre repetida da narração que os outros não escutam. Essa narrativa, explicam os sobreviventes, nunca consegue realmente 
dizer a experiência inenarrável do horror. As narrativas das memórias traumáticas ilustram as dificuldades que pesam sobre a (im) possibilidade de narração, sobre a (im) possibilidade da experiência comum, enfim, sobre a (im) possibilidade da transmissão da própria experiência e do lembrar.

Essa circunstância torna-se ainda mais clara no dilema enfrentado por Paul Celan, poeta nascido na Romênia e que escrevia em alemão. O próprio Celan, de ascendência judaica, foi prisioneiro de um campo de trabalhos forçados. Seus pais foram mortos num campo de concentração. Como sobrevivente, o poeta teve de enfrentar o paradoxo de escrever na língua daqueles responsáveis pela morte de seus pais. Como observado por Lima (2000, p. 274), poderia a língua materna de Celan desligar-se "da marca assassina que nela se produzira?"3.

Os limites da linguagem também foram testados no caso da ditadura militar no Brasil. Ginzburg, em "Escritas da tortura", ilustra, a partir da análise de testemunhos de vítimas da tortura, a impossibilidade de recurso à sintaxe convencional, a dificuldade de medir a passagem do tempo, a "dificuldade de se sustentar uma imagem clara do 'Eu' em cena tão dolorosa”, a fragmentação da narrativa. Os testemunhos de vítimas da tortura retratam a quebra da articulação primária entre o corpo e a linguagem (Ginzburg, 2010, pp. 141, 146-48).

\section{A construção de memórias: a recuperação do passado}

Os rastros mnésicos constituem apenas uma pequena parte dos eventos passados. A memória é seletiva, pois nem tudo

\footnotetext{
3 Veja a importante análise que Lima propõe para o poema "Todtnauberg", em que Celan expressa a decepção gerada pelo encontro com Martin Heidegger em sua casa na Floresta Negra. O poema denota a expectativa (não atendida) de que Heidegger se referisse ao holocausto. O filósofo, no encontro, permaneceu silente. Em nota pessoal de agradecimento, Heidegger escreveria a Celan: "Desde então, calamos muitas coisas um ao outro" (Lima, 2000, p. 275).
} 
pode ser registrado no transcorrer histórico. Analisando os regimes totalitários do século XX, Todorov (2002) constata um grande esforço no sentido de se manipular a memória ao negar o acesso à informação. No caso do Terceiro Reich, os esforços para suprimir as evidências são claramente ilustrados pela tentativa de destruir, em 1944, as câmaras de gás e o crematório de Auschwitz. Os esforços voltados à supressão da informação não se limitaram à destruição de vestígios pelos nazistas. A população foi continuamente intimidada para impedir a procura de informações, bem como a sua divulgação.

Além disso, o nazismo explorou, por meio da propaganda e do uso de eufemismos, o potencial da linguagem como forma de controle da memória. A propaganda antissemita apoiava e reforçava todas as medidas antijudaicas de forma que cada ato sucessivo, mesmo que ineficaz no propósito declarado, aprofundava o abismo entre 198 os judeus e os demais cidadãos (Bauman, 1998, p. 150; Arendt, 1994, p. 199).

Outro uso parasitário da linguagem é evidenciado nos eufemismos. A Seção de Administração e Economia, denominação oficial do departamento encarregado da destruição dos judeus europeus no quartel geral das SS (tropas paramilitares nazistas), pode ser explicada por referência às notórias regras de discurso, destinadas a desorientar tanto observadores causais como os criminosos menos decididos (Bauman, 1998, p. 33). Por outro lado, deve-se reconhecer que tal denominação refletia fielmente o significado da atividade para a organização burocrática do Terceiro Reich.

[A atividade desempenhada pelo departamento], exceto pela repugnância moral do seu objetivo [...], não diferia em sentido formal [o único que pode ser expresso na linguagem da burocracia] de todas as outras atividades organizadas que eram traçadas, monitoradas e 
supervisionadas por seções administrativas e econômicas “ordinárias” (Bauman, 1998, p. 33) ${ }^{4}$.

A importância da propaganda e dos eufemismos não apenas para a concretização do holocausto, mas também para sua rememoração foi sentida vinte anos depois de Auschwitz, no julgamento de Adolf Eichmann. Numa tentativa de recuperação da memória do holocausto em Israel, Eichmann continuava a expressar-se por meio de eufemismos ou, em suas palavras, por meio do oficialês (cf. Arendt, 2009, p. 61). "Questão judaica”, "solução política”, "uma zona inteiramente desembaraçada dos judeus", "a evacuação de todos os judeus para o campo de Auschwitz", "fatigar-me com todos esses assuntos de deportações" são alguns exemplos de eufemismos usados por Eichmann. É, preferível, explicava Eichmann, "dizer a coisa com mais humanidade” (apud Arendt, 2009).

A linguagem não foi capaz de transmitir o terror do nazismo. Ela foi modificada para ocultá-lo, transformá-lo em algo irreal. Ao proteger-se com fronteiras que a linguagem não ultrapassa, o totalitarismo se impõe de forma absoluta. "Quando as palavras são incapazes de expressar o que acontece e de transportar essa narrativa para outro lugar e outro tempo, esse fracasso faz com que o sistema permaneça num isolamento perfeito" (Tafalla, 2003, p. 127) ${ }^{5}$. Esse isolamento reflete-se, por exemplo, na (im) possibilidade de a vítima exprimir-se a partir desses eufemismos ou de apropriar-se da lingua tertii imperii $i^{6}$ para compartilhar sua experiência.

\footnotetext{
4 Atentando para os riscos da crença moderna na racionalidade, Bauman (1998, p. 33) continua: "as câmaras de gás, sedutoramente chamadas de 'banheiros', eram uma visão bem-vinda depois de dias e dias em imundos vagões para gado”.

5 Todas as traduções de citações em língua estrangeira foram feitas livremente pelos autores deste artigo.

6 Expressão cunhada por Victor Klemperer em seu liro de 1947. Trata-se de uma análise da estrutura mental fascista a partir do estudo da manipulação da língua alemã pelos detentores do poder na Alemanha. Veja, por exemplo, Oelsner (2002).
} 
Concebida como um discurso de elucidação, que objetiva a compreensão do passado, a memória não é o oposto de esquecimento. Ela é resultado da interação entre esquecimento e lembrança. De todos os sinais deixados pelo passado, apenas alguns são escolhidos para serem perpetuados. Uma vez estabelecidos os fatos, é preciso interpretá-los, relacioná-los uns aos outros, reconhecer causas e efeitos, formular semelhanças e gradações, oposições. No caso do holocausto, as condições desumanas dos campos de concentração descritas por Levi, além de reduzirem o acesso das vítimas à informação, limitaram a capacidade de relacionar os fatos selecionados pela memória ${ }^{7}$.

Essas dificuldades resultaram para Agamben (2000) na possibilidade de apenas os Muselmänner serem testemunhas do campo. No entanto, até mesmo a possibilidade de testemunha dos Muselmänner parece ser questionada em alguns textos de Levi. Em Os afogados e os sobreviventes, Levi (2004, 200 p. 14) afirma: "a história do Lager foi escrita quase exclusivamente por aqueles que, como eu próprio, não tatearam seu fundo. Quem o fez não voltou, ou então sua capacidade de observação ficou paralisada pelo sofrimento e pela incompreensão".

No caso do Brasil, o recurso aos eufemismos caracterizou não apenas o período ditatorial, mas também o processo de passagem para a democracia. Fico (2004, p. 33), por exemplo, indica a utilização do termo "operações de segurança" para designar "prisões, interrogatórios, torturas e extermínios, praticados pelo 'Sistema Codi-Doi', pelos órgãos de informações dos ministérios militares (CIE, Cisa e Cenimar) e pelos departamentos de ordem política e social estaduais". Silva Filho (2008, p. 162) relata que o regime foi ainda mais cuidadoso, afirmando que as expressões

\footnotetext{
7 Langer (2000, p. 236) afirma que as memórias do holocausto são testemunhos do dano permanente causado pelo desastre, "uma ferida horrível na psique dos poucos que sobreviveram".
} 
"interrogado" e "prestou esclarecimento" nas fichas da DOPS (Departamentos de Ordem Política e Social) dizem respeito à prática da tortura. A permanência dos eufemismos no processo de democratização é retratada na Lei de Anistia, de 1979, que emprega o termo "ausentes", oriundo da dogmática jurídico-civilista, para se referir aos desaparecidos. Essa terminologia, explica-nos Silva Filho (2008, p. 162), conota uma morte presumida e não um assassinato cujo cadáver não é encontrado.

"A tensão entre linguagem e silêncio, entre o que falar e o que calar" foi essencial para a manutenção do regime ditatorial (Ginzburg, 2010, p. 143). Pautada na ideologia da segurança nacional, a ditadura militar reforçava a ideia de que a guerra ocorria no interior do espaço social. O inimigo era "o subversivo clandestino que mora na casa ao lado" (Ginzburg, 2010, p. 143). Ao controlar a linguagem, o regime ditatorial controlava a memória social, o que é possível lembrar e como lembrar. Nesse contexto, os testemunhos possibilitados pelos vários mecanismos de justiça de transição implementados no Brasil permitem questionar tais limites.

\section{Usos da memória}

Seria a compreensão, facilitada pela memória, recomendável diante de tamanha atrocidade? As dificuldades postas por essa questão são tematizadas por Todorov a partir de dois momentos da reflexão de Levi (1988). Em um primeiro momento, Levi afirma que compreender é quase justificar. Todorov (2002, p. 146) reconhece que, para as vítimas, a compreensão pode implicar "uma identificação com o carrasco, ainda que parcial e provisória, e isso pode acarretar uma destruição de si mesmo". Esse risco não pode ser desconsiderado. Não se deve exigir que a vítima compreenda, que a vítima perdoe aquele que violou seus direitos. 
A relação automática entre compreender e justificar não deve ser estabelecida de forma geral. Compreender o mal não significa, necessariamente, justificá-lo. O próprio Levi (1988, p. 27) observa, posteriormente, que "para um homem laico, tal como eu, o essencial é compreender e fazer compreender. É tentar, precisamente, desmistificar essa representação maniqueísta do mundo em branco e

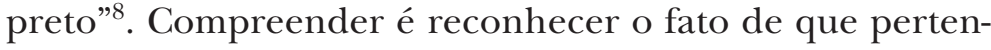
cemos todos à mesma humanidade. A compreensão do mal é necessária para impedir-lhe o retorno. A memória, ao permitir a compreensão do mal, não destrói a vítima. Ao impedir futuras violações de direitos humanos, ela tem o potencial de nutrir a vida, o convívio.

Essas duas perspectivas ilustram que a reconstrução do passado não é capaz de definir, por si, o seu uso futuro. A memória, por ser seletiva, escolhe entre as informações recebidas de acordo com determinados critérios. Esses crité202 rios, conscientemente ou não, trazem em si a possibilidade de uso do passado.

Ao ser evocada em um memorial, por exemplo, a memória não é apenas uma lembrança dos mortos, ela permite a identificação dos mortos como heróis ou vítimas, como possuidores de honra, fé, lealdade. Ao supor uma morte violenta, provocada por indivíduos, a justificativa da morte também é trabalhada. O sentido da morte é estabelecido pelos sobreviventes e não pelos mortos (Koselleck, 2002, pp. 285-326). Nesse contexto, o sentido da memória do holocausto ou do período ditatorial no Brasil pode mudar de acordo com quem a estabelece: trata-se de um sentido transitório.

\footnotetext{
8 Esse aspecto é claramente explorado por Levi (2004) no livro Os afogados e os sobreviventes, no capítulo intitulado "A zona cinzenta". Trata-se de uma expressão que designa inicialmente todos aqueles que não podem ser classificados simplesmente como prisioneiros ou guardas, isto é, os presos que ajudavam os guardas superiores. Mas, além disso, ela inclui todos os habitantes do campo de concentração, prisioneiros e guardas, cujas complexidades não se deixam reduzir à divisão $\mathrm{bom} / \mathrm{mau}$.
} 
A memória não é responsável apenas por nossas convicções, mas também por nossos sentimentos ${ }^{9}$. Ela diz respeito a uma reconstrução social que constitui sentimentos de continuidade ao formar identidades durante o seu transcorrer histórico.

[P] odemos, portanto, dizer que a memória é um elemento constituinte do sentimento de identidade, tanto individual como coletivo, na medida em que ela é também um fator extremamente importante do sentimento de continuidade e de coerência de uma pessoa ou de um grupo em sua reconstrução de si (Pollak, 1992, p. 204) ${ }^{10}$.

Esse processo de reconstrução gera mutações na memória que correspondem às implicações do presente com o passado. Ao movimentar-se socialmente, a memória também é alterada. Todorov denomina essa fase do trabalho de rememoração de aproveitamento: a instrumentalização do passado voltada a objetivos atuais. No lugar do caráter espontâneo e natural, ressaltam-se os esforços deliberados de reconstrução empreendidos pela memória, que respondem usualmente a demandas e interesses políticos precisos. Percebe-se, assim, a imbricação da memória com a força da ação humana para a configuração das relações de poder. A memória é um meio fundamental da ação coletiva e um veículo de poder.

\footnotetext{
9 Sobre a relação entre memória e sentimento, Todorov (2000, p. 26) explica: "experimentar uma revelação impactante sobre o passado, sentindo a obrigação de reinterpretar radicalmente a imagem que alguém tinha sobre as pessoas próximas a ele e sobre si mesmo, é uma situação perigosa que pode se transformar em algo insuportável, e que será refutada de forma veemente".

${ }^{10}$ Para o autor, em vários momentos, Halbwachs insinua a existência de um processo de negociação para conciliar memória coletiva e memórias individuais. Esse reconhecimento do caráter problemático de uma memória coletiva anuncia a inversão de perspectiva que marca os trabalhos atuais sobre esse fenômeno: "numa perspectiva construtivista, não se trata mais de lidar com os fatos sociais como coisas, mas de analisar como os fatos sociais se tornam coisas, como e por quem eles são solidificados e dotados de duração e estabilidade" (Pollak, 1989, p. 4).
} 
Le Goff (1992, p. 476) analisa a memória coletiva como elemento intimamente relacionado às disputas por poder que prevalecem em espaços específicos. Essa relação pode ser evidenciada a partir da imposição de determinadas leituras da memória coletiva, as quais podem recriar, reforçar ou destruir determinadas identidades sociais. Atos coletivos podem, consequentemente, ser direcionados através da redefinição das particularidades dos membros que integram um grupo.

Tornar-se senhor da memória e do esquecimento é uma das grandes preocupações das classes, dos grupos, dos indivíduos que dominaram e dominam as sociedades históricas. Os esquecimentos e os silêncios da história são reveladores desses mecanismos de manipulação da memória (Le Goff, 1984, p. 13) ${ }^{11}$.

No contexto da Segunda Guerra Mundial, “assim que a Alemanha se tornou mais uma vez uma Nação-Estado, iniciou-se uma busca contínua por um passado útil” (Bartov, Grossmann, Nolan, 2005, p. 24). Esforços de documentação, a política da memória, buscaram contestar e confundir a categoria de vítima, a princípio evidente nas análises da Segunda Guerra. O número de alemães expulsos de territórios orientais pelo Exército Vermelho foi comparado ao número de vítimas dos campos de extermínio, o sofrimento dos soldados alemães que recuavam no final da guerra foi relatado pelos alemães em uma prosa angustiada e empática que não era utilizada em referência aos judeus que foram

11 Zuckermann (1988-89, p. 45; grifos no original), analisando o uso da memória por Israel, propõe uma terminologia nova: "Israel não pode ser acusada de ter esquecido o holocausto, porque o país nunca chegou a se lembrar dele. Desde o início, Israel reprimiu o holocausto e utilizou uma imagem-holocausto como uma ilustração histórica quase concreta do direito à formação, existência e desenvolvimento de um Estado sionista em todas as suas fases, incluindo a ocupação a partir de 1967". 
vítimas desses mesmos soldados. Houve uma aspiração ao estatuto de vítima no debate público.

No caso do Brasil, o discurso de setores mais ligados à repressão militar postula a legitimidade do regime autoritário, referindo-se à revolução em vez de ao golpe. Há uma grande resistência em se admitir a ocorrência de torturas e desaparecimentos forçados. Há, senão a negação das violações de direitos humanos cometidas, um enorme silêncio. Por outro lado, Silva Filho (2008) alerta para o fato de que, com as tentativas de recuperação da memória, vastos setores da sociedade cedem à tentação de simplesmente propor outra história no lugar da oficial. No entanto, essa história alternativa também reflete uma concatenação causal entre os fatos apresentados e um desenrolar contínuo, além da redução da identidade dos indivíduos aos papéis de vítima ou perpetrador.

Os desafios que o holocausto coloca para a compreensão humana, inclusive para a moderna justiça criminal, permitiram a atribuição do status de vítima a todos os judeus ${ }^{12}$, como a carta de Arendt para Jaspers, de 1946, ilustra:

Sua definição da política nazista como criminosa... a mim parece questionável. Os crimes do nazismo, na minha

\footnotetext{
12 Nesse particular, não deixa de ser interessante observar a discussão acerca do papel dos colaboradores judeus e pelo zelo dos Judenräte (conselhos judeus) no holocausto. Refletindo sobre o silêncio dos sobreviventes dos campos de concentração que, após serem libertados, retornaram à Alemanha, Pollak (1989, p. 7) entende que o "silêncio sobre o passado está ligado em primeiro lugar à necessidade de encontrar um modus vivendi com aqueles que, de perto ou de longe, ao menos sob a forma de consentimento tácito, assistiram à sua deportação. [...] Contudo, essa atitude é ainda reforçada pelo sentimento de culpa que as próprias vítimas podem ter, oculto no fundo de si mesmas. É sabido que a administração nazista conseguiu impor à comunidade judia uma parte importante da gestão administrativa de sua política antissemita [...]".
} 
opinião, fulminam os limites do direito; e é exatamente isso que os torna monstruosos. Para esses crimes, não há punição que seja suficientemente severa [...]. Essa culpa, contrariamente a toda culpa penal, supera e destrói todo e qualquer sistema jurídico... nós simplesmente não temos instrumentos para lidar (no plano humano ou político) com uma culpa que está além do crime e uma inocência que está além da bondade ou da virtude. Não sei como resolveremos isso, pois os alemães estão agora sobrecarregados com milhares, dezenas, centenas de milhares de pessoas que não podem ser adequadamente punidas dentro do sistema jurídico; e nós, judeus, estamos sobrecarregados com milhões de inocentes, e é por isso que todo judeu vivo hoje pode se ver como a inocência personificada (apud Kohler e Saner, 1993, p. 52).

Todavia, a história demonstrou que a condição de víti206 ma no passado não impede a violação dos direitos de outros. Foi a utilização da memória, como fonte de legitimação da atuação do Estado de Israel, que conduziu à publicação do artigo "A plea for forgetting", por Elkana. Para o autor, sobrevivente de Auschwitz:

Não há tarefa política e pedagógica mais importante para os líderes de Israel do que permanecer ao lado da vida, de se dedicar ao futuro, e não recorrer constantemente aos símbolos, cerimônias e lições do holocausto. Os líderes devem erradicar o domínio dessa memória histórica sobre nossas vidas (apud Zuckermann, 1988-89, p. 43).

A fixação no passado impede o bem-viver no presente. Quando a leitura da memória traumática ocorre de forma literal, ela permanece intransitiva, proporcionando a formação de associações causais diretas. Espera-se que, ao se 
retirar as causas, ao se identificar e punir os perpetradores, as consequências do ato desaparecerão, o sofrimento atual desaparecerá, os riscos atuais dissipar-se-ão.

Esse contexto permite, segundo Elkana, uma identificação automática entre judeu e vítima, mesmo diante das violações das regras de direito internacional cometidas em território palestino. Para Elkana, a brutalidade vigente nas relações entre Israel e Palestina é resultado de um medo existencial "que reside numa interpretação muito particular do holocausto, como acreditar que o mundo inteiro está contra nós e que somos nós as eternas vítimas" (apud Zuckermann, 1988-89, p. 43). O ressentimento gerado pelo uso literal da memória do holocausto impede a justiça e a paz.

No entanto, "nunca mais" é a rejeição clara ao holocausto. A expressão Brasil: nunca mais, usada no título da primeira tentativa de se tematizar as violações de direitos humanos cometidas durante o período ditatorial no Brasil, traz à tona um ideal. A concretização desse ideal exige que a rememoração dos crimes cometidos e das violações de direitos humanos, sua atual representação, não tenha uma função literal. É necessário que a memória remeta à vida de seres humanos, à sanção de leis internacionais e ao estabelecimento de limites numa época de crescente violência e desrespeito ao direito. Nesse sentido, a exigência de memória deve levar em conta as grandes dificuldades que pesam sobre a possibilidade da transmissão e do lembrar. Se essas dificuldades forem desconsideradas, o discurso de memória corre o risco de ser rapidamente apropriado por uma história oficial (alternativa), em que outros inimigos são construídos.

Essa memória exige muito mais de nós, como se fosse alguém que "inscrevendo um possível alhures fora do par mortífero algoz-vítima, dá novamente um sentido humano ao mundo" (Piralian, 1999, p. 541). No sonho de Primo Levi, deveria ser função do ouvinte, ao permitir que as 
memórias de Auschwitz abalassem sua linguagem, retomar e transmitir essa história em palavras diferentes. Essa apropriação seria um primeiro passo na tentativa de se escrever uma nova história, uma história em que o extermínio de outros grupos não se repita ${ }^{13}$. O potencial democrático da memória do holocausto encontra-se, portanto, em seu caráter exemplar.

O caráter exemplar das memórias traumáticas permite que a atuação no presente não se paute em uma permanente identificação de um indivíduo, grupo ou Estado como vítima, capaz de legitimar novas violações de direitos. Ele impede que vítimas de injustiças, por mais terríveis que sejam, se instalem no centro da história e da memória comum, reclamando um protagonismo que force ao esquecimento de situações similares. Ela impede, por exemplo, a aceitação da tortura de outros grupos.

A memória traumática tem o potencial de ser utiliza208 da como um modelo para compreensão de situações novas, com agentes diferentes. A função exemplificativa generaliza, mas de maneira limitada: ela não faz desaparecer a identidade dos fatos, mas os relaciona, estabelecendo diferenças e semelhanças. A memória do genocídio de 6 milhões de judeus durante a Segunda Guerra Mundial pode tornar-se capaz de evitar o extermínio de outros grupos, ao ampliar, inclusive, a perspectiva crítica da (in)ação histórica da comunidade internacional. A memória do período ditatorial no Brasil também tem um potencial problematizador, político.

Assim, no momento em que a comunidade internacional se depara com questões ligadas ao extermínio em

\footnotetext{
${ }^{13}$ Sobre fazer história, Koselleck (2006a, p. 245) afirma "os homens são responsáveis pelas histórias em que estão envolvidos, não importando se têm ou não têm culpa nas consequências de suas ações. É a incomensurabilidade entre a intenção e o resultado que os homens têm que assumir, e isto confere um sentido enigmaticamente verdadeiro à expressão 'fazer história'”.
} 
massa (como em Darfur) e à reutilização do campo de prisioneiros (o caso de Guantánamo), e o Brasil, com grupos de extermínio, desaparecimentos forçados e a prática da tortura, torna-se ainda mais decisivo o recurso à memória. Não se trata aqui de uma memória inteiramente "externa", baseada numa leitura desinteressada do passado, tampouco uma memória puramente "subjetiva", calcada na experiência de um indivíduo ou de um grupo. Não é possível um testemunho "exterior" ou "interior". Por outro lado, é viável uma mediação entre esses elementos.

Analisando o filme Shoah (de 1985), de Claude Lanzmann, Shoshana Felman defende:

Pois que, para o testemunho de fora, mesmo na dor de sua sincera empatia e simpatia, a verdade do interior resta a verdade de uma exclusão - "não era um mundo, não era a humanidade" -, não é realmente possível dizer a verdade, testemunhar do exterior [...] Parece-me que a postura impossível e a tensão testemunhal do filme inteiro é precisamente não ser nem simplesmente no interior, nem simplesmente no exterior, mas, paradoxalmente, ao mesmo tempo no interior e no exterior: o filme tenta abrir uma via e lançar uma ponte que não existia durante a guerra e não existe hoje entre o interior e o exterior - para colocá-los em contato e em diálogo (apud Lima, 2000, p. 264; grifos no original).

Identificar as estratégias de exclusão, observar as decisões seletivas do direito e da política, buscar compreender as demandas que envolvem a pauta dos direitos humanos são desafios que a memória do holocausto e os esforços de construção da memória do regime ditatorial no Brasil apresentam ao nosso tempo. No caso do Brasil, essa relação é necessária para que possamos buscar compreender a permanência e o crescimento da violência na 
sociedade brasileira, bem como o silêncio que a circunda. Nesse sentido, restaurar a memória, para além de um processo de reparação individual, assume um potencial democrático.

\section{Cristiano Paixão}

é professor de pós-graduação em Direito, Estado e Constituição/História Constitucional e Historiografia na Universidade de Brasília (UnB).

\section{Giovanna Maria Frisso}

é professora de pós-graduação em Direito Constitucional na Universidade Federal Fluminense (UFF).

\section{Bibliografia}

ABRÃO, P. 2002. “Apresentação”. In: MEYER, E. P. N. Ditadura e responsabilização: elementos para uma justiça de transição no Brasil.

Belo Horizonte: Arraes Editores.

AGAMBEN, G. 2000. Ce qui reste d'Auschwitz. Paris: Payot \& Rivages.

ARENDT, H. 1994. "The image of hell”. In: Essays in understanding

1930-1954: formation, exile and totalitarianism. New York: Schocken Books.

2009. Eichmann em Jerusalém. São Paulo: Companhia das Letras.

BARTOV, O.; GROSSMANN, A.; NOLAN, M. 2005. "Introdução". In: BARTOV, O.; GROSSMANN, A.; NOLAN, M. (orgs.). Crimes de guerra: culpa e negação no século XX. Rio de Janeiro: Difel.

BAUMAN, Z. 1998. Modernidade e holocausto. Rio de Janeiro: Jorge Zahar Ed. BOSI, E. 1987. Memória e sociedade: lembranças de velhos. São Paulo: T. A. Queiroz.

DE GIORGI, R. 2006. "A memória do direito". In: Direito, tempo e memória. São Paulo: Quartier Latin.

DUVIGNAUD, J. 2006. "Prefácio". In: HALBWACHS, M. A memória coletiva. São Paulo: Centauro.

FICO, C. 2004. "Versões e controvérsias sobre 1964 e a ditadura militar". Revista Brasileira de História, v. 24, n. 47, pp. 29-60.

GINZBURG, J. 2010. "Escritas da tortura”. In: TELLES, E.; SAFATLE, V. (orgs.). O que resta da ditadura. São Paulo: Boitempo.

HALBWACHS, M. 2006. A memória coletiva. São Paulo: Centauro. 
KOHLER, L.; SANER, H. 1993. Hannah Arendt/Karl Jaspers:

correspondence 1926-1969. London: Harvest Book. (Carta 43).

KOSELLECK, R. 2002. "War memorials: identity formations of the survivors". In: The practice of conceptual history: timing history, spacing concepts. Stanford: Stanford University Press.

. 2006a. "Sobre a disponibilidade da história". In: Futuro passado: contribuição à semântica dos tempos históricos. Rio de Janeiro: Contraponto. Cap. 11.

. 2006b. "Terror e sonho - Anotações metodológicas para as experiências do tempo no Terceiro Reich”. In: Futuro passado: contribuição à semântica dos tempos históricos. Rio de Janeiro: Contraponto. Cap. 12.

LANGER, L. 2000. "Redefining heroic behavior". In: BARTOV, O. The Holocaust: origins, implementation, aftermath. London: Routledge. Cap. 11.

LE GOFF, J. 1984. "Memória”. In: Enciclopédia Einaudi. v. I. Porto: Imprensa Nacional. 1992. História e memória. Campinas: Ed. Unicamp.

LEVI, P. 1988. É isto um homem? Rio de Janeiro: Rocco. 2004. Os afogados e os sobreviventes. 2. ed. Tradução de Luiz Sérgio Henriques. São Paulo: Paz e Terra.

LIMA, L. C. 2000. Mimesis: desafio ao pensamento. Rio de Janeiro:

Civilização Brasileira.

OELSNER, M. B. P. 2002. Victor Klemperer e sua obra LTI - Lingua Tertii Imperii. Dissertação de mestrado. São Paulo: USP.

PIRALIAN, H. 1999. "Ecriture(s) du genocidaire”. In: COQUIO, C. (org.). Parler des camps, penser les génocides. Paris: Albin Michel.

POLLAK, M. 1989. "Memória, esquecimento, silêncio”. Estudos Históricos, Rio de Janeiro, v. 2, n. 3, pp. 3-15. 1992. "Memória e identidade social". Estudos Históricos, Rio de Janeiro, v. 5, n. 10, pp. 200-12.

POWER, S. 2004. Genocídio: a retórica americana em questão. São Paulo: Companhia das Letras.

SEIXAS, J. A. 2001. "Percursos de memórias em terras de história: problemáticas atuais”. In: BRESCIANI, S.; NAXARA, M. (orgs.). Memória e (res)sentimento: indagações sobre uma questão sensível. São Paulo: Ed. Unicamp.

SILVA Filho, J. C. M. 2008. "O anjo da história e a memória das vítimas: o caso da ditadura militar no Brasil”. Veritas, v. 53, n. 2, pp. 150-78.

SONTAG, S. 2011. Ao mesmo tempo. Lisboa: Quetzal. 
TAFALLA, M. 2003. "Recordar para no repetir: el nuevo imperativo categórico de T. W. Adorno.” In: MARDONES, J.; MATES, R. (eds.). La ética ante las víctimas. Barcelona: Anthropos Editorial.

TODOROV, T. 2000. Los abusos de la memoria. Barcelona: Paidós Ibérica. . 2002. Memória do mal, tentação do bem: indagações sobre o século XX. São Paulo: Arx.

ZUCKERMANN, M. 1988-89. "The curse of forgetting: Israel and the holocaust”. Telos, New York, n. 78, pp. 43-54. 


\section{USOS DA MEMÓRIA: AS EXPERIÊNCIAS DO HOLOCAUSTO E DA DITADURA NO BRASIL}

CRISTIANO PAIXÃO

GIOVANNA MARIA FRISSO

Resumo: Observa-se hoje uma série de esforços voltados para a recuperação da memória do período ditatorial no Brasil. A partir da discussão da memória do holocausto, o artigo busca chamar a atenção para a necessária reflexão acerca do potencial que a memória do período ditatorial apresenta para a promoção da reconciliação nacional. Ciente do potencial libertador/restaurador da rememoração, este artigo discute, além da dificuldade de comunicar da memória traumática, os riscos relacionados ao seu uso. Ao discutir esses temas, esperamos contribuir para que os sentidos atribuídos às memórias de milhares de vítimas possibilitem a construção de projetos que modifiquem o presente e o futuro, de forma a evitar a manutenção de situações de violação de direitos humanos.

Palavras-chave: Memória; Linguagem; Democracia; Holocausto; Ditadura Brasileira.

\section{USES OF MEMORY: EXPERIENCES OF HOLOCAUST AND BRAZILIAN DICTATORSHIP}

Abstract: Various efforts aimed at recovering the memory of dictatorial period have been undertaken in Brazil nowadays. Drawing from the debates related to the memory of the Holocaust, this article calls attention to the need to discuss the potential risks and benefits that the understanding of the memory of the dictatorial period as a means of promoting the promotion of national reconciliation presents. Aware of the potential for liberation/ restoration of remembrance, this article discusses, besides the difficulty of communicating traumatic memory, the risks related 
to its use. When discussing these issues, we hope to contribute to the meanings attributed to the memories of thousands of victims allowing the construction of projects that change the present and the future, and avoid further human rights violations.

Keywords: Memory; Language; Democracy; Holocaust; Brazilian Dictatorship.

Recebido: 19/01/2015 Aprovado: 04/12/2015 